\title{
Spectrophotometric Determination of Drugs with MBTH as Oxidative Coupler Reaction: A review
}

\author{
Samar Ahmed Darweesh ${ }^{1}$, Rokayia Samir Al-Khalisy ${ }^{1}$ \\ ${ }^{1}$ Lecturer, Ph.D. Chemistry Department/College of Education for Pure Science-Ibn Al-Haitham/Baghdad \\ University/Iraq
}

\begin{abstract}
A widespread range of oxidative coupler reactions have been approved for drugs. Majority of these reactions are color producing reactions.

Generally, spectrophotometric procedures are easy to achieve, little-cost, sensitive and selective, however each spectrophotometric way has its advantages and weaknesses, which are an essentialfeature when choosing the technique for estimation of drugs.

So, the purpose of objective in this paper is to review numerouspresent techniques for spectrophotometric estimation of drugs with MBTH and to compare the modern spectrophotometric ways and to summarize their advantages and weaknesses.
\end{abstract}

Keywords: Spectrophotometric determination, Drug, 3-Methyl-2-Benzothiazolinone Hydrazone, Oxidative coupler reaction.

\section{Introduction}

Oxidative Coupler Reaction: Oxidative coupler reaction includes combination of two organic materials or further in existence of suitable oxidizing agent and satisfactory reaction circumstances. After the oxidation process of these ingredients occurs, leading to the creation of intermediary compounds which rejoin with each other to providedyed product that can be measured spectrally, and therefore can advantage from these interactions for the aims of quantification of a number of compounds ${ }^{(1)}$.

The oxidative coupler reaction first detected by

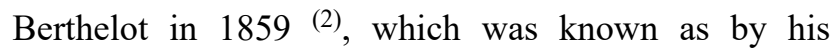
name also called indophenol reaction. The blue color of indophenol created by phenol and hypochlorite in the existence of ammonia provided the maximum absorbance at $630 \mathrm{~nm}^{(3)}$. The mechanization of reaction shown below ${ }^{(4)}$ :

Spectrophotometric analysis for the determination of drugs: Absorption spectrophotometry is one of greatestbeneficial tools obtainable to the chemist for quantitative analysis. This is for the reason that it has wide-ranging applicability, great sensitivity and modest to high selectivity, perfect accuracy and simplicity as well as suitability.

Colorimetric techniques can selectively convert a drug, its impurity, or metabolite so that the spectrum is moved to the visible region and away from interfering affected via additional drug, formation constituents, or biological materials, thus talking a more degree of specificity. Furthermore, a drug with slight or no beneficial absorption can be extra sensitivity estimated by adjusting it to further high absorptive chromophore ${ }^{(5)}$.

3-Methyl-2-Benzothiazolinone Hydrazone (MBTH) (Besthorn's reagent or Sawicki's reagent) ${ }^{(6)}$ : 3-Methyl-2-Benzothiazolinone Hydrazone was initially produced by Besthron in 1910. Huning and Fritsch have designated the oxidative coupler of this reagent with aromatic amines, heterocyclic bases, phenols, and compounds containing active methylene group to produce extremely dyedyields in 1957. In 1961 Sawicki et al. introduced MBTH in analytical chemistry as a sensible reagent for the estimation of carbonyl compounds. It can be also utilized for the revealing and estimation of phenols, polyhydroxy compounds, aldehydes, aromatic amines and amino hetero aromatic compounds including indoles, carbazoles and phenothiazines. The chemical construction of MBTH is shown in Figure 2. 


$$
\mathrm{NH}_{3}+\mathrm{OCI}^{-} \longrightarrow \mathrm{H}_{2} \mathrm{NCl}+\mathrm{OH}^{-}
$$

Ammonia Hypochlorite ion Chloramine hydroxide ion


(Indophenol blue dye)

Figure (1): The mechanization of indophenol formation.<smiles>Cn1/c(=N\N)sc2ccccc21</smiles>

Figure 2:The chemical construction of (MBTH).

General mechanism for the reaction of $\mathrm{MBTH}^{(6)}$ : MBTH misses two electrons and one proton on oxidation, under reaction conditions, creating an electrophilic intermediate, which is assumed to be the active coupler species. The intermediaryrejoins with amine (or) phenol by electrophilic attack on the mainly nucleophilic place up in the aromatic ring of amine or phenol (i.e., para or ortho position) and the intermediary is oxidized in the existence of oxidant to get the dyedcomponents. Figure 3 shows the general reaction with MBTH.

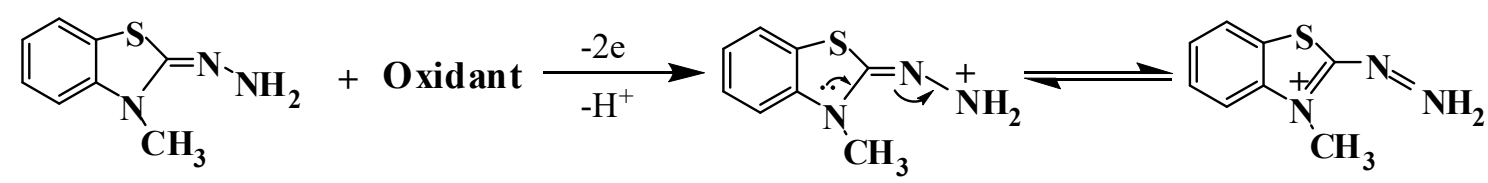

MBTH

Electrophilic intermediate

(Active coupling species)

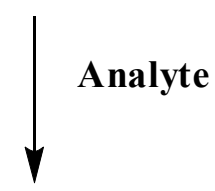

\section{Colored product}

Figure 3: General reaction with MBTH 
Spectrophotometricanalysisfor thedetermination of drugs with (MBTH)as oxidative coupling reagent: (MBTH) initiallypresented as a reagent for aldehydes. Subsequent MBTH use was comprehensive to different organic compounds (example: phenols, aryl amines and different N- and S- heterocyclic compound $)^{(6)}$. In latest years, the utilize of spectrophotometric method were useful in the analysis of drugs with MBTH as oxidant reagent. A survey of the literature mentioned numerous spectrophotometric techniques for analysis of drugs using MBTH as oxidative coupling reagent.

Table (1): Some spectrophotometric determination of drugs with (MBTH).

\begin{tabular}{|c|c|c|c|c|c|}
\hline No. & Drug compounds (Trade name) & $\lambda_{\max }(\mathrm{nm})$ & Linear range $\left(\mu \mathrm{g} \cdot \mathrm{ml}^{-1}\right)$ & $\begin{array}{l}\text { Molar absorptivity } \\
\quad(\text { l.mol-1.cm }\end{array}$ & Ref. \\
\hline 1 & (Nifedipine) & 685 & $1-19$ & $2.77 \times 10^{4}$ & 7 \\
\hline 2 & (Tenofovir disoproxil fumarate) & 626.5 & $50-250$ & $1.65 \times 10^{4}$ & 8 \\
\hline 3 & (Fenofibrate) & 596 & $2-5$ & $1.91 \times 10^{4}$ & 9 \\
\hline 4 & (Chloramphenicol) & 620 & $10-60$ & $1.00 \times 10^{4}$ & 10 \\
\hline 5 & (Nitrofurantoin) & 610 & $0.5-30$ & $6.59 \times 10^{3}$ & 11 \\
\hline 6 & (Selegiline Hydrochloride) & 629 & $10-85$ & $0.98 \times 10^{4}$ & 12 \\
\hline 7 & $\begin{array}{l}\text { (Meloxicam) and } \\
\text { (Tenoxicam) }\end{array}$ & $\begin{array}{l}619 \\
619\end{array}$ & $\begin{array}{c}0.2-10 \\
0.1-5\end{array}$ & $\begin{array}{l}15.82 \times 10^{4} \\
16.61 \times 10^{4}\end{array}$ & 13 \\
\hline 8 & (lornoxicam) & 620 & $0.008-0.04$ & $1.39 \times 10^{4}$ & 14 \\
\hline 9 & (Pregabalin) & 668 & $50-350$ & $4.202 \times 10^{4}$ & 15 \\
\hline 10 & (Prulifloxacin) & 580 & $1-5$ & $1.34 \times 10^{4}$ & 16 \\
\hline 11 & (Atorvastatin) & 566 & $2-20$ & $3.36 \times 10^{4}$ & 17 \\
\hline 12 & (Bicalutamide) & 630 & $10-60$ & $0.35 \times 10^{4}$ & 18 \\
\hline 13 & (Lamivudine) & 659 & $1-8$ & $0.28 \times 10^{3}$ & 19 \\
\hline 14 & (Aceclofenac) & 592 & $1-100$ & $1.00 \times 10^{4}$ & 20 \\
\hline
\end{tabular}

\section{Conclusion}

The techniques described for spectrophotometric estimation of drugs alongside with MBTH display perfect analytical possibility. So these techniques can be suggested for the repetitive analysis of these drugs in quality controller laboratories and they may be successfully used for the estimation of drugs in pharmaceutical preparations.

Acknowledgement: Thanks for everyone who helped me accomplish this research.

Ethical Clearance: The Research Ethical Committee at scientific research by ethical approval of both MOH and MOHSER in Iraq.

\section{Conflict of Interest: None}

Funding: Self-funding

\section{References}

1. Liu D, Sun WL and Macgregor PMM. Exchange strategy forstructure eluddation of pharmaceutical impurities.J Pharm BiomedAnal.2007; 44:53.

2. Jassim LS. Spectrophotometric determination of resorcinol in real water samples and pharmaceutical formulations after reaction with paminophenol. Thesis, University of Baghdad. 2006.

3. Ciom NR. Drinking water and health, disinfectants and disinfectant by products. Nat Aca Pre.1987;7:91. 
4. Carlberg SR. New Baltic manual: with new method for sampling and analyses of physical, chemical and biological parameters. International Council for the Exploration of the Sea. 1972.

5. Adegoke OA. Chemical Derivatization Methodologies for UV-Visible Spectrophotometric Determination of Pharmaceuticals. Int J Pharm Sci Rev Res. 2012;14(2):6-24.

6. Ravisankar P, Sulthana MDS, Babu PS, Basha SKA, Aswini R, Swathi V, Sultana SKM, Prasanna MSL, Navyasri N and Thanuja. Comprehensive Review of Important Analytical Reagents Used in Spectrophotometry. Indo Am J of Pharm Res. 2017; 7(5):8716-8744.

7. Tulasamma $P$ and Venkateswarlu P. Spectrophotometric determination of nifedipine in pharmaceutical formulations, serum and urine samples via oxidative coupling reaction. Arab J of Chem. 2016; 9:1603-1609.

8. Varsha MS, Babu NR, Padmavathi Y and Kumar PR. Development of new spectrophotometric method for estimation of tenofovir disoproxil fumarate using MBTH reagent. Int Curr Pharm J.2015; 4(4): 378-381.

9. KuttySV, Eapen SC, Baby A and Prasanth VG. Development of Validation UV-Visible Spectrophotometric Method for The Estimation of Fenofibrate in Pure and Pharmaceutical Formulation Using MBTH Reagent. Int J of Pharm Res and BioSci.2012; 1(1):1-10.

10. Suguna P, Sathyanarayana B and Naidu NVS. Validated Spectrophotometric Method for The Determination of Choramphenicol in Pure and in Its Dosage Form. Int J of Cur Pharm Res. 2016; 8(3):22-27.

11. Hadi $\mathrm{H}$ and Mouayed M. Spectrophotometric Determination of Nitrofurantoin Drug in its Pharmaceutical Formulations Using MBTH as a Coupling Reagent. Iraqi J Pharm Sci. 2016; 25(2):7-14.
12. Divya K and Narayana B. Novel Spectrophotometric Method for the Determination of Selegiline Hydrochloride in Bulk and Its Pharmaceutical Preparation. Hin Pub Cor. 2014; 2014:1-7.

13. Mallikarjuna H, Shivaprasad KH and Venugopala Reddy KR and Lokesh KS. Spectrophotometric Determination of Some Nonsteroidal AntiInflammatory Drugs by Oxidative Coupling Reaction.Aus J of Anal and Pharm Chem. 2016; 3(3):1-6.

14. Venumadhav E, Neha T, Bhargavi P, Nishat A, Swetha $A$ and Devala Rao G.Novel spectrophotometric method for the determination of lornoxicam in pharmaceutical dosage forms. Biomed \& Pharmaco J. 2010; 3(2):417-420.

15. Sowjanya K, Thejaswini JC, GurupadayyaBM and Indupriya M. Spectrophotometric Determination of Pregabalin Using Gibb's and MBTH reagent in Pharmaceutical Dosage Form. Der Pharm Chemica. 2011; 3(1):112-122.

16. RavisankarP.Fivenovel spectrophotometricmethod for quantitative determination of Prulifloxacin in pure and pharmaceutical formulations. Asi $\mathrm{J}$ of Biomed and Pharm Sci. 2015; 5(48), 1-13.

17. Ashour S. New Kinetic Spectrophotometric Method for Determination of Atorvastatin in Pure and Pharmaceutical Dosage Forms, Ashour. Pharm Anal Acta.2013; 4(5):1-6.

18. Balaram VM, Rao JV, Ali Khan MM, Sharma JVC and Sreedevi K. Visible Spectrophotometric Determination of Bicalutamide in Bulk Drug and Pharmaceutical Formulations. Int J Chem Sci. (2009) 7(3):1606-1612.

19. Rahul Reddy MB, Gurupadayya BM and Anil Kumar T. Spectrophotometric determination of lamuvidine using acidic dye and coupling reagent. Ind J of Chemi Tech. 2011; 18:431-438.

20. Bose A, Dash PP, and Sahoo MK. Simple spectrophotometric method for estimation of aceclofenac from bulk and formulations. Pharm Method. 2010; 1(1):57-60. 